\title{
Upregulation of miR-125b is associated with poor prognosis and trastuzumab resistance in HER2-positive gastric cancer
}

\author{
MINGHUA SUI $^{1 *}$, AIHONG JIAO $^{1 *}$, HUIYUAN ZHAI $^{2}$, YAN WANG $^{3}$, \\ YONG WANG ${ }^{4}$, DENGJUN SUN ${ }^{1}$ and PENG LI ${ }^{1}$

\begin{abstract}
Departments of ${ }^{1}$ Oncology, ${ }^{2}$ Gastrointestinal Surgery and ${ }^{3}$ Hematology, Yuhuangding Hospital, Yantai, Shandong 264001; ${ }^{4}$ Department of General Surgery, General Hospital of Ping Coal Group, Pingdingshan, Henan 467000, P.R. China
\end{abstract}

Received December 21, 2015; Accepted March 10, 2017

DOI: $10.3892 / \mathrm{etm} .2017 .4548$

\begin{abstract}
Gastric cancer is one of the most common types of human cancer associated with a poor prognosis. MicroRNAs (miRs), a class of non-coding RNAs that are 18-25 nucleotides in length, act as key regulators in gene expression, and have been implicated in various human cancer types. miR-125b has been implicated in the malignant progression of gastric cancer. However, the association between miR-125b expression, clinicopathological characteristics and trastuzumab resistance in human epidermal growth factor receptor 2 (HER2)-positive gastric cancer remains unclear. In the current study, in situ hybridization data demonstrated that 81.8\% (108/132) of gastric cancer tissues exhibited positive expression of miR-125b, while only $26.3 \%$ (10/38) of non-tumor gastric tissues were miR-125b-positive. Reverse transcription-quantitative polymerase chain reaction data indicated that the expression level of miR-125b was markedly increased in gastric cancer tissues compared with non-cancerous gastric tissues. Furthermore, the miR-125b level was significantly associated with tumor (T) stage, lymph node metastasis, distant metastasis and TNM stage of gastric cancer $(\mathrm{P}<0.05)$. Increased miR-125b expression predicated poor prognosis in patients with gastric cancer. For HER2-positive gastric cancer, the upregulation of miR-125b expression was significantly associated with advanced malignant progression, as well as a poor prognosis $(\mathrm{P}<0.05)$. Furthermore, data from the present study indicated that the increased miR-125b level was significantly associated with trastuzumab resistance in HER2-positive gastric cancer $(\mathrm{P}<0.05)$. Therefore, the current study suggests that miR-125b
\end{abstract}

Correspondence to: Professor Huiyuan Zhai, Department of Gastrointestinal Surgery, Yuhuangding Hospital, 20 Yuhuangding East Road, Yantai, Shandong 264001, P.R. China

E-mail: drzhaihuiyuan@sina.com

*Contributed equally

Key words: gastric cancer, microRNA-125b, prognosis, human epidermal growth factor receptor 2 , trastuzumab may become a potential biomarker for predicting prognoses and clinical outcomes in patients with HER2-positive gastric cancer that receive trastuzumab treatment.

\section{Introduction}

Gastric cancer is one of the most common cancer types diagnosed in humans with a poor prognosis $(1,2)$. Although significant progress has been achieved, the clinical outcomes for gastric cancer are not yet satisfactory $(1,2)$. Dysfunctions of oncogenes or tumor suppressors, including microRNAs (miRs) and human epidermal growth factor receptor 2 (HER2), have been implicated in the development and drug resistance of gastric cancer $(3,4)$. Thus, an understanding of the molecular mechanisms is urgently required for the development of more effective treatments for patients with gastric cancer.

miRs are non-coding RNAs, 18-25 nucleotides in length, that typically have a suppressive role in regulating gene expression by directly binding to the 3 -untranslational region of their target mRNAs and leading to mRNA degradation or translation inhibition $(5,6)$. Deregulation of specific miRs, associated with tumor development and progression, has been observed in gastric cancer along with drug resistance $(7,8)$. Therefore, investigating the roles of these miRs may help improve the diagnosis and treatment of gastric cancer.

miR-125b is located at chromosome 11q24 and chromosome $21 \mathrm{q} 21$, the so-called fragile sites that are frequently deleted (9). It has been reported to be significantly downregulated in osteosarcoma (10), breast cancer (11), ovarian cancer (12), and hepatocellular carcinoma (13), suggesting a tumor suppressive role. However, miR-125b is upregulated in colorectal cancer (14), prostate cancer (15) and non-small-cell lung cancer (16), suggesting that miR-125b has dual roles depending on the type of cancer. miR-125b has been implicated in gastric cancer; two studies reported that miR-125b was among the most upregulated miRs in gastric cancer tissues compared with non-tumour gastric tissues $(17,18)$. In addition, miR-125b was identified to be upregulated in gastric cancer tissues and cell lines where it significantly promoted proliferation, migration and invasion by downregulating the expression of protein phosphatase 1 catalytic subunit- $\alpha$ (PPP1CA) and upregulating retinoblastoma ( $\mathrm{Rb})$ phosphorylation (19). Furthermore, it was demonstrated in a previous 
study that miR-125b is involved in the malignant progression of gastric cancer and increased miR-125b expression predicated a poor prognosis for patients with gastric cancer (19). These results suggest that miR-125b has an oncogenic role in gastric cancer. By contrast, Fassan et al (20) demonstrated that miR-125a-5p and miR-125b were significantly downregulated in intestinal-type gastric cancer. Accordingly, the exact role of miR-125b in gastric cancer, specifically in some subtypes, is yet to be fully uncovered. Moreover, trastuzumab is an important target drug for patients with human epidermal growth factor receptor 2 (HER2)-positive breast and gastric cancers (21). However, the role of miR-125b in trastuzumab resistance in the HER2-positive gastric remains unclear.

The present study aimed to investigate the expression of miR-125b in gastric cancer and analyzed the association between miR-125b expression and clinicopathological characteristics, prognosis and trastuzumab resistance in the HER2-positive subtype.

\section{Materials and methods}

Tissue samples and clinical data. Gastric tissues from a total of 132 cases of gastric cancer and 38 non-cancerous cases (21 male and 17 female; mean age, 47.5 \pm 8.5 ) were collected at the Yuhuangding Hospital (Yantai, China) between November 2008 and September 2012 who were admitted due to gastrohelcosis. The mean age of patients with gastric cancer was $54.5 \pm 10.8$ years and of the 132 patients, 75 were male and 57 were female. Among patients with HER2-positive gastric cancer, 28 cases received trastuzumab $(6 \mathrm{mg} / \mathrm{kg}$, once every 3 weeks, for 6 months; Roche Diagnostics, Basel, Switzerland) until the time of tissue collection. Clinicopathological characteristics of the patients with gastric cancer were evaluated according to the TNM system (22), as summarized in Table I. Overall survival (OS) was defined as the time from diagnosis to mortality or the date last known alive. Informed consent was obtained from all patients or their dependents involved. The present study was approved by the Committee on the Ethics of Yuhuangding Hospital (Yantai, China).

In situ hybridization. The probe for in situ hybridization of miR-125b was synthesized by Sangon Biotech, Co., Ltd. (Shanghai, China). An enhanced Sensitive in situ hybridization detection kit I (POD; Wuhan Boster Biological Technology, Ltd., Wuhan, China) was used to perform in situ hybridization, according to manufacturer's protocol. Slides were deparaffinized, dehydrated with xylene, put through an ethanol gradient (100, 95, 90, 80 and $70 \%$, each for $5 \mathrm{~min})$, and rinsed with $\mathrm{dH}_{2} \mathrm{O}$. Following treatment with $3 \% \mathrm{H}_{2} \mathrm{O}_{2}$ for 15 min and washing twice with $\mathrm{dH}_{2} \mathrm{O}$, the slides were incubated with pepsin solution (enhanced Sensitive in situ hybridization detection kit I; Wuhan Boster Biological Technology, Ltd.) for $10 \mathrm{~min}$ at $37^{\circ} \mathrm{C}$ and washed three times with phosphate-buffered saline (PBS) and once with $\mathrm{dH}_{2} \mathrm{O}$ at room temperature. Following this, the slides were incubated with prehybridization solution (enhanced Sensitive in situ hybridization detection kit I; Wuhan Boster Biological Technology, Ltd.) at $37^{\circ} \mathrm{C}$ for $3 \mathrm{~h}$ and then with the miR-125b probe $(2 \mu \mathrm{g} / \mathrm{ml}$; Yearthbio, Changsha, China) overnight at $55^{\circ} \mathrm{C}$. Subsequently, the slides were incubated in $2 \mathrm{X}$ saline sodium citrate (SSC)
Table I. Clinicopathological characteristics of patients with gastric cancer $(\mathrm{n}=132)$.

\begin{tabular}{lc}
\hline Characteristic & Value \\
\hline Age, mean \pm SD & $54.5 \pm 10.8$ \\
Sex & \\
Male & $56.8(75 / 132)$ \\
Female & $43.2(57 / 132)$ \\
T stage & \\
T1-2 & $53.8(71 / 132)$ \\
T3-4 & $46.2(61 / 132)$ \\
Lymph node metastasis & \\
Present & $60.6(80 / 132)$ \\
Absent & $39.4(52 / 132)$ \\
Distant metastasis & \\
Present & $10.6(14 / 132)$ \\
Absent & $89.4(195 / 132)$ \\
TNM stage & \\
I & $6.1(8 / 132)$ \\
II & $57.6(76 / 132)$ \\
III & $25.0(33 / 132)$ \\
IV & $11.4(15 / 132)$ \\
\hline
\end{tabular}

Data are presented as $\%(\mathrm{n} / \mathrm{N})$ unless otherwise stated. SD, standard deviation; $\mathrm{T}$, tumor.

for $30 \mathrm{~min}$ at $37^{\circ} \mathrm{C}$, washed once with $0.5 \mathrm{X} \mathrm{SSC}$ for $15 \mathrm{~min}$ and washed three times with $0.2 \mathrm{X}$ SSC for $10 \mathrm{~min}$. Slides were incubated with normal goat serum (1:50; Yearthbio) at $37^{\circ} \mathrm{C}$ for $30 \mathrm{~min}$ and then with biotin-antidigoxin $\operatorname{IgG}(1: 200$; 21563; Yearthbio) for $1.5 \mathrm{~h}$ at $37^{\circ} \mathrm{C}$. Subsequently, the slides were washed three times with PBS, followed incubation with Streptavidin-Biotin-Complex (1:100; 21511; Yearthbio) and biotin-peroxidase $\left(1: 100 ; 21435\right.$; Yearthbio) for $30 \mathrm{~min}$ at $37^{\circ} \mathrm{C}$. Slides were visualized with 3,3'-diaminobenzidine (DAB; Fuzhou Maixin Biotech, Co., Ltd., Fuzhou, China) for 5 min and counterstained with hematoxylin for $2 \mathrm{~min}$. Slides were dried and observed using a CX23 microscope (magnification, x200; Olympus Corp., Tokyo, Japan).

Immunohistochemical staining. Expression of HER2 was evaluated using immunohistochemical staining (22). Sections with a thickness of $4 \mu \mathrm{m}$ were deparaffinized and subjected to heat-induced antigen retrieval using citrate buffer for $22 \mathrm{~min}$ using a microwave oven. The sections were incubated at $37^{\circ} \mathrm{C}$ for $2 \mathrm{~h}$ with primary anti-HER2 antibody (1:100; ab16901; Abcam, Cambridge, MA, USA). Sections were washed with PBS for 10 min and incubated with the secondary antibody (1:10,000; ab150116; Abcam) for $60 \mathrm{~min}$ at room temperature. The reaction was developed using substrate DAB, counterstained with hematoxylin, and observed under a CX23 microscope (magnification, $\mathrm{x} 200$ ).

Evaluation of staining data. All tissue sections were scored independently by two experienced pathologists, and the 

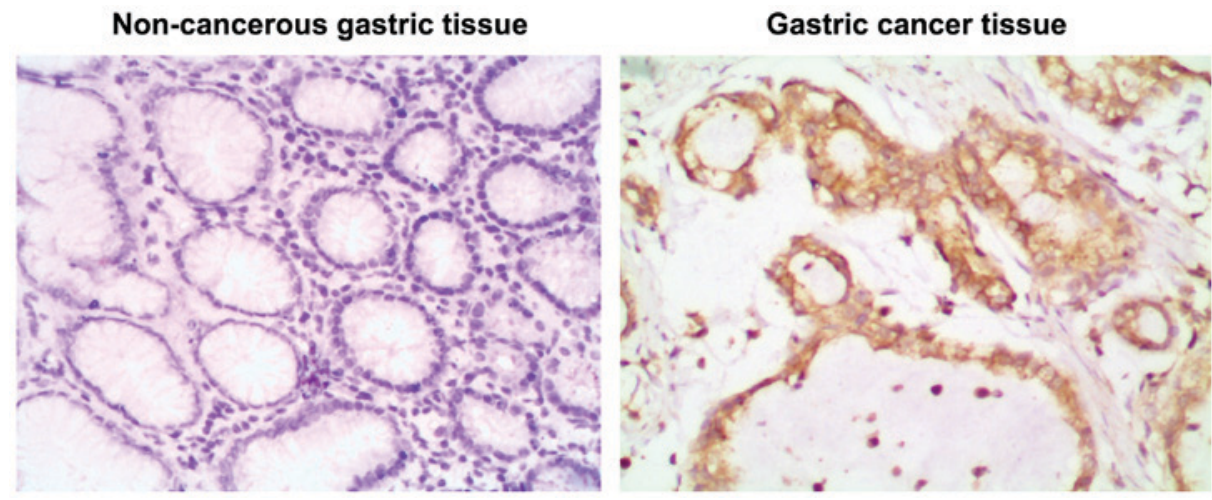

Figure 1. In situ hybridization data indicated miR-125b-positive expression in the cytoplasm and nucleus of gastric cancer cells. Purple stain indicates miR-125b. Magnification, x200.

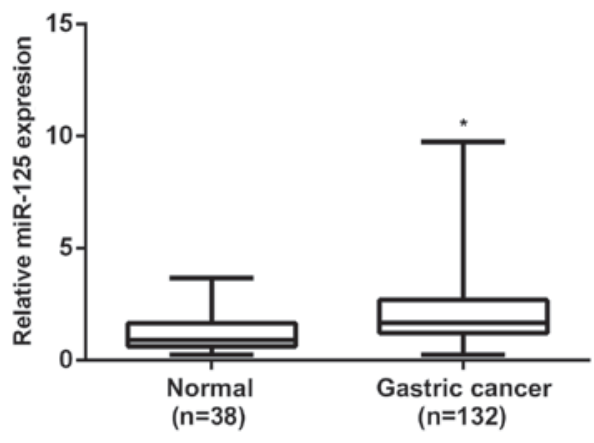

Figure 2. Reverse transcription-quantitative polymerase chain reaction data demonstrated that miR-125b expression was significantly increased in gastric cancer tissues compared with non-cancerous gastric tissues. Data are presented as the mean \pm standard deviation. ${ }^{*} \mathrm{P}=0.001$ vs. normal.

average score was calculated. For evaluating the expression of miR-125b and HER2 in gastric cancer tissues, the staining extent and intensity were evaluated. The scoring system was as follows: Percentage of positively stained cells was scored as 0 (negative, - ), 1 ( $>0$ and $\leq 25 \%$ of cells positive, weak, + ), 2 $(>25$ and $\leq 75 \%$ of cells positive, moderate, ++$)$ and 3 ( $>75 \%$ of cells positive, strong, +++ ). Scores of 0 or 1 were considered as low expression, whereas scores of 2 or 3 were considered as high expression.

Reverse transcription-quantitative polymerase chain reaction $(R T$ - $q P C R)$. Total RNA $(10 \mu \mathrm{l})$ was extracted using TRIzol reagent (Thermo Fisher Scientific, Inc., Waltham, MA, USA), according to the manufacturer's protocol. For miR-125b expression analysis, PCR was performed using a PrimeScript miRNA RT-PCR kit (Takara Biotechnology, Co., Ltd., Dalian, China) with an ABI PRISM 7500 Fast Real-Time PCR system (Thermo Fisher Scientific, Inc.), according to the manufacturer's protocol. Primer sequences for miR-125b were as follows: Forward, 5'-TGCGCTCCTCTCAGTCCCTGAGA-3' and reverse, 5-'TGCGCTCCTCTCAGTCCCTGAG-3. U6 (sequences not provided by the manufacturer) was used as the internal reference. qPCR was performed using SYBR-Green (Invitrogen; Thermo Fisher Scientific, Inc.). Reaction conditions were $95^{\circ} \mathrm{C}$ for $10 \mathrm{~min}$, followed by 45 cycles of $95^{\circ} \mathrm{C}$ for $15 \mathrm{sec}$ and $60^{\circ} \mathrm{C}$ for $15 \mathrm{sec}$. Relative expression was analyzed by the $2^{-\Delta \Delta \mathrm{Cq}}$ method (23). Experiment were performed in triplicate.

Statistical analysis. Data are presented as the mean \pm standard deviation. GraphPad Prism 5 software (GraphPad Software, Inc., La Jolla, CA, USA) was used for statistical analysis. Differences in miR-125b expression between gastric cancer and non-cancerous gastric tissue were analyzed via Student's t-test. Contingency data were analyzed via $\chi^{2}, \chi^{2}$ test for trend or Fisher's exact tests. OS estimates over time were calculated using the Kaplan-Meier method with log-rank test. $\mathrm{P}<0.05$ was considered to indicate a statistically significant difference.

\section{Results}

miR-125b is significantly upregulated in gastric cancer. To elucidate the role of miR-125b in gastric cancer, the present study examined the level of miR-125b expression in gastric cancer tissues and non-cancerous gastric tissues using in situ hybridization and RT-qPCR. As presented in Fig. 1, positive staining of miR-125b was observed in the cytoplasm and nuclei of gastric cancer cells. Positive expression of miR-125b was observed in $81.8 \%$ (108/132) of gastric cancer tissues. However, only $26.3 \%$ (10/38) of non-tumor gastric tissues were miR-125b-positive, indicating that miR-125b is more frequently expressed in gastric cancer tissues compared with non-tumor gastric tissues.

RT-qPCR was performed to determine the expression levels of miR-125b in gastric cancer tissues and non-tumor gastric tissues, respectively. The results of the present study indicate that miR-125b levels were significantly increased in gastric cancer tissues, when compared with non-cancerous gastric tissues ( $\mathrm{P}=0.001 ;$ Fig. 2). According to the results of the present study, miR-125b is significantly upregulated in gastric cancer.

Association between miR-125b levels and clinicopathological features of gastric cancer. The association between the level of miR-125b and clinicopathological characteristics of gastric cancer was analyzed using a univariate $\chi^{2}$ test, which included age, sex, T stage, lymph node metastasis, distant metastasis and TNM stage data. No significant difference was observed between miR-125b expression and the age, sex or distant 
Table II. Association between low $(n=79)$ and high $(n=29)$ miR-125b expression and clinicopathological characteristics in patients with breast cancer.

\begin{tabular}{|c|c|c|c|}
\hline Variable & High expression ( score $\geq 1$ ) & Low expression (score $<1$ ) & $\chi^{2} \mathrm{P}$-value \\
\hline Age, mean $\pm \mathrm{SD}$ & $52.3 \pm 7.2$ & $53.7 \pm 8.8$ & 0.796 \\
\hline Sex & & & 0.652 \\
\hline Male & $48(60.8)$ & $19(65.5)$ & \\
\hline Female & $31(39.2)$ & $10(34.5)$ & \\
\hline T stage & & & $<0.001^{\mathrm{a}}$ \\
\hline $\mathrm{T} 1-2$ & $32(40.5)$ & $23(79.3)$ & \\
\hline T3-4 & $47(59.5)$ & $6(20.7)$ & \\
\hline Lymph node metastasis & & & $0.001^{\mathrm{a}}$ \\
\hline Present & $60(75.9)$ & $12(41.4)$ & \\
\hline Absent & $19(24.1)$ & $17(58.6)$ & \\
\hline Distant metastasis & & & 0.416 \\
\hline Present & $12(15.2)$ & $2(6.9)$ & \\
\hline Absent & $67(84.8)$ & $27(93.1)$ & \\
\hline TNM stage & & & $0.009^{\mathrm{a}}$ \\
\hline I-II & $47(59.5)$ & $25(86.2)$ & \\
\hline III-IV & $32(40.5)$ & $4(13.8)$ & \\
\hline
\end{tabular}

Data are presented as $\mathrm{N}(\%)$ unless otherwise stated. ${ }^{a} \mathrm{P}<0.05 . \mathrm{miR}$, microRNA; SD, standard deviation.
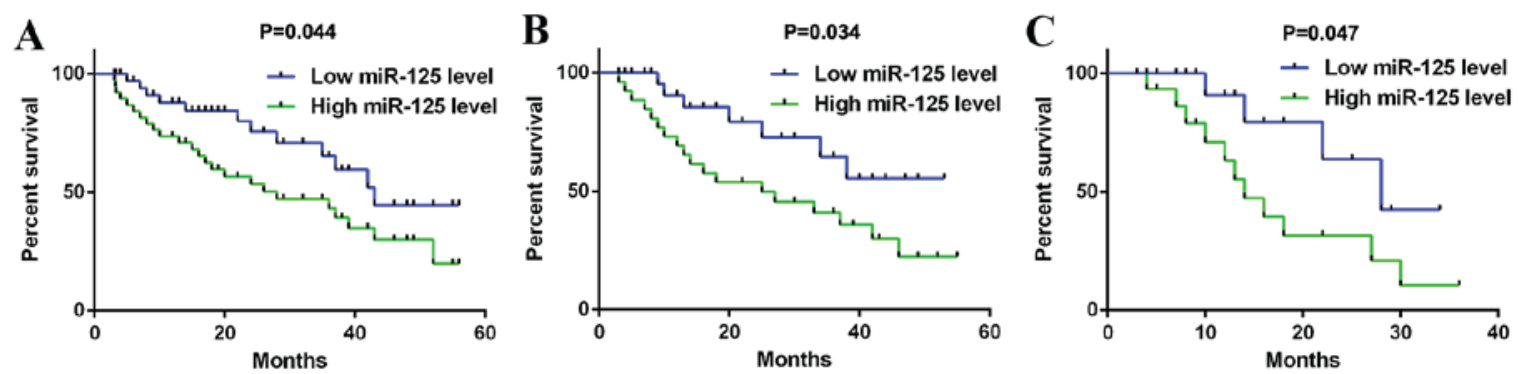

Figure 3. Kaplan-Meier curves indicating the survival rate of patients with gastric cancer. (A) Kaplan-Meier curves indicated that the overall survival rate for patients with gastric cancer and high miR-125b expression was significantly lower than for patients with low miR-125b expression ( $\mathrm{P}=0.044)$. (B) Kaplan-Meier curves indicated that the overall survival rate for patients with HER2-positive gastric cancer and high miR-125b expression were significantly lower than for patients with low miR-125b expression $(\mathrm{P}=0.034)$. (C) Kaplan-Meier curves indicated that for patients with gastric cancer treated with trastuzumab, the overall survival rate was significantly lower for those patients with high miR-125b expression, when compared with patients with low miR-125b expression ( $\mathrm{P}=0.047)$. HER2, human epidermal growth factor receptor 2; miR, microRNA.

metastasis of gastric cancer $(\mathrm{P}>0.05$; Table II). However, miR-125b expression was significantly associated with $\mathrm{T}$ stage $(\mathrm{P}<0.001)$, lymph node metastasis $(\mathrm{P}=0.001)$ and clinical TNM stage $(\mathrm{P}=0.009)$, suggesting that the upregulation of miR-125b is associated with the malignant progression of gastric cancer (Table II).

The association between miR-125b level and the prognosis of patients with gastric cancer was analyzed. OS duration ranged from 3 to 65 months. Data from the current study indicated that the OS rate of patients with gastric cancer exhibiting high miR-125b expression was significantly lower than those with low miR-125b expression ( $\mathrm{P}=0.044$; Fig. 3A). Multivariate cox regression analysis was completed and indicated that the miR-125b expression $(\mathrm{P}=0.001)$, lymph node metastasis $(\mathrm{P}=0.004)$, distant metastasis $(\mathrm{P}=0.001)$ and TNM stage $(\mathrm{P}=0.005)$ may be independent prognostic factors for gastric cancer (data not shown). However, no significant differences were observed in the OS rate of patients with gastric cancer regarding the age, sex and tumor stage $(\mathrm{P}>0.05)$.

Association between miR-125blevels and clinicopathological characteristics in HER2-positive gastric cancer. HER2 has been identified as a direct target of miR-125b and is involved in the development and progression of gastric cancer (20). Therefore, the association between miR-125b levels and clinicopathological characteristics in HER2-positive gastric cancer was assessed. As presented in Table III, among the 82 cases of HER2-positive gastric cancer patients, miR-125b expression was significantly associated with the $\mathrm{T}$ stage $(\mathrm{P}=0.015)$, lymph node metastasis $(\mathrm{P}=0.014)$ and TNM stage $(\mathrm{P}=0.002)$. However, no significant differences were observed between miR-125b levels and the age, sex or distant 
Table III. Association between miR-125b expression and clinicopathological characteristics in patients with HER2-positive breast cancer.

\begin{tabular}{|c|c|c|c|}
\hline \multirow[b]{2}{*}{ Variables } & \multicolumn{2}{|c|}{ miR-125b expression } & \multirow[b]{2}{*}{$\chi^{2}$ test $\mathrm{P}$-value } \\
\hline & $\begin{array}{c}\text { High }(\text { score } \geq 1) \\
n=58\end{array}$ & $\begin{array}{c}\text { Low }(\text { score }<1) \\
n=24\end{array}$ & \\
\hline Age, mean \pm SD & $52.7 \pm 6.2$ & $53.3 \pm 7.1$ & \\
\hline Sex & & & 0.639 \\
\hline Male & $33(56.9)$ & $15(62.5)$ & \\
\hline Female & $25(43.1)$ & $9(37.5)$ & \\
\hline T stage & & & $0.015^{\mathrm{a}}$ \\
\hline $\mathrm{T} 1-2$ & $24(41.4)$ & $17(70.8)$ & \\
\hline T3-4 & $34(58.6)$ & $7(29.2)$ & \\
\hline Lymph node metastasis & & & $0.014^{\mathrm{a}}$ \\
\hline Present & $41(70.7)$ & $10(41.7)$ & \\
\hline Absent & $17(29.3)$ & $14(58.3)$ & \\
\hline Distant metastasis & & & 1.000 \\
\hline Present & $8(13.8)$ & $3(12.5)$ & \\
\hline Absent & $50(86.2)$ & $21(87.5)$ & \\
\hline TNM stage & & & $0.002^{\mathrm{a}}$ \\
\hline I-II & 27 (46.6) & $20(83.3)$ & \\
\hline III-IV & $31(53.4)$ & $4(16.7)$ & \\
\hline
\end{tabular}

Data are presented as $\mathrm{N}(\%)$ unless otherwise stated. ${ }^{\mathrm{a}} \mathrm{P}<0.05$. miR, microRNA; HER2, human epidermal growth factor receptor $2 ; \mathrm{SD}$, standard deviation.

metastasis of patients with HER2-positive gastric cancer (P>0.05; Table III).

Furthermore, the OS rate of patients with HER2-positive gastric cancer and higher miR-125b expression was significantly reduced compared with those with lower miR-125b expression ( $\mathrm{P}=0.034$; Fig. $3 \mathrm{~B})$. This suggests that the upregulation of $\mathrm{miR}-125 \mathrm{~b}$ expression predicts a poor prognosis in patients with HER2-positive gastric cancer.

Upregulation of miR-125b expression predicts poor prognosis in patients with HER2-positive gastric cancer who received trastuzumab treatment. Trastuzumab is a targeted drug used for HER2-positive cancer (21). In the current study, the effect of miR-125b expression on the clinical outcome of trastuzumab treatment in HER2-positive gastric cancer was examined. Among patients with HER2-positive gastric cancer, 28 cases received trastuzumab treatment. Our data indicated that the OS rate of patients with HER-2-positive gastric cancer and higher miR-125b expression was significantly reduced, when compared with those with low miR-125b expression $(\mathrm{P}=0.047$; Fig. $3 \mathrm{C})$. This suggests that low expression of miR-125b is beneficial for the prognosis of patients with HER-2-positive gastric cancer, while a higher miR-125b level may predicate poor prognosis.

\section{Discussion}

miR-125b has been reported to be deregulated in various types of human cancer. It is significantly downregulated in osteosarcoma (10), breast cancer (11), ovarian cancer (12), and hepatocellular carcinoma (13), but upregulated in colorectal cancer (14), prostate cancer (15) and non-small-cell lung cancer (16), suggesting dual roles of miR-125 in different cancer types. In the present study, miR-125b expression was demonstrated to be significantly increased in gastric cancer tissues compared with non-cancerous gastric tissues, which is consistent with previous studies $(17,19)$. However, the underlying mechanism by which miR-125b expression is upregulated in gastric cancer remains unclear. Bousquet et al (24) reported that the translocation $\mathrm{t}(2 ; 11)(\mathrm{p} 21 ; \mathrm{q} 23)$ led to increased expression of miR-125b in myelodysplastic syndrome and acute myeloid leukemia. Similarly, the translocation $\mathrm{t}(11 ; 14)(\mathrm{q} 24 ; \mathrm{q} 32)$ led to the upregulation of miR-125b in B-cell progenitor acute lymphoblastic leukemia (25). Therefore, it is reasonable that chromosomal translocation may also result in higher expression of miR-125b expression in gastric cancer, and future studies should aim to verify this speculation.

Data from the current study indicated that, although the higher miR-125b expression was not associated with sex or distant metastasis of gastric tumors, it was significantly associated with the $\mathrm{T}$ stage, lymph node metastasis and clinical TNM stage. A previous study also indicated that miR-125b expression was positively associated with the tumor size, depth of invasion, lymph node metastasis and clinical TNM stage of gastric tumors (19). In addition, data from their study and the present study indicated that increased miR-125b expression predicted poor prognosis in gastric cancer patients (19). Based 
on these results, the upregulation of miR-125b is potentially involved in the malignant progression of gastric cancer.

Song et al (26) performed a consensus clustering analysis of miR profiles for 90 different gastric cancer tissues and identified a key miR regulatory network potentially driving the poor-prognosis gastric cancer subtype, which was characterized by the overexpression of epithelial-to-mesenchymal transition markers. Within this regulatory network, miR-125b was observed to target genes that were significantly associated with survival. These data are consistent with the results of the current study, in that a high miR-125 expression is associated with a poor prognosis in patients with gastric cancer. Furthermore, Wu et al (19) conducted an in vitro investigation and demonstrated that miR-125b overexpression significantly promoted the proliferation, migration and invasion of gastric cancer cells by inhibiting the expression of PPP1CA and upregulating $\mathrm{Rb}$ phosphorylation. This revealed an important molecular mechanism by which miR-125b has an oncogenic role in gastric cancer.

HER2 is a member of the epidermal growth factor receptor family of receptor tyrosine kinases (27-30). Although HER2 has no ligand binding domain of its own and therefore cannot bind growth factors, it is able to bind to other ligand-bound EGF receptor family members to form a heterodimer. This heterodimer is able to stabilize ligand binding and enhance kinase-mediated activation of downstream signaling pathways, such as mitogen-activated protein kinase and phosphatidylinositol-3 kinase, the aberrant activation of which has key roles in the development and progression of human cancer (27-30). Furthermore, amplification and/or overexpression of HER2 has been identified in common human cancer types, including breast, ovarian and gastric cancer, and has been developed into an important therapeutic target (31-33). Fassan et al (20) reported that HER2 status correlated inversely with miR-125 expression and dysregulation of miR-125a-5p/125b. Also indicating that HER2 is an early event in intestinal-type gastric cancer (16). However, to the best of our knowledge, no previous study has focused on the association between miR-125b expression and the clinicopathological characteristics in HER2-positive gastric tumors. In the present study, high miR-125b expression was demonstrated to be significantly associated with $\mathrm{T}$ stage, lymph node metastasis, and TNM stage, although no significant association was observed between miR-125b expression and the age, sex or distant metastasis of HER2-positive gastric tumors. Data from the current study suggests that miR-125b should be considered among the therapeutic targets in HER2-positive gastric cancer.

In addition, accumulating evidence has suggested that miR-125b participates in the regulation of drug resistance in human cancer types. Vilquin et al (34) demonstrated that increased miR-125b expression predicted a poor prognosis in letrozole resistant breast cancer and overexpression of miR-125b conferred the resistance of breast cancer MCF-7 cells to letrozole and anastrozole. As trastuzumab has been commonly used as a targeted drug for HER2-positive cancer, the present study speculated that miR-125b may also affect the clinical outcomes of patients with HER2-positive gastric cancer who received trastuzumab treatment. Indeed, the results of the present study indicate that high miR-125b expression is significantly associated with a poor prognosis of patients with HER2-positive gastric cancer that are treated with trastuzumab, suggesting that miR-125b is involved in the regulation of drug resistance. Therefore, targeting miR-125b may be beneficial for improving the treatment of trastuzumab in patients with HER2-positive gastric cancer. Yagishita et al (35) also reported that cytotoxic drugs, such as cisplatin, induced significant upregulation of HER2 through the downregulation of miR-125b, which in turn acted as a novel therapeutic target for trastuzumab-mediated cellular cytotoxicity in small cell lung cancer.

In conclusion, the present study demonstrates that the expression of miR-125b is significantly increased in gastric cancer, and its upregulation is associated with the malignant progression and poor prognosis of patients with gastric cancer, including HER2-postive gastric cancer. In addition, upregulation of miR-125b expression predicts poor prognosis in patients with HER2-positive gastric cancer who received trastuzumab treatment. Therefore, the miR-125b/HER2 axis may become a potential therapeutic target for gastric cancer.

\section{References}

1. Siegel RL, Miller KD and Jemal A: Cancer statistics, 2017. CA Cancer J Clin 67: 7-30, 2017.

2. Torre LA, Bray F, Siegel RL, Ferlay J, Lortet-Tieulent J and Jemal A: Global cancer statistics, 2012. CA Cancer J Clin 65: 87-108, 2015

3. Li Z, Lei H, Luo M, Wang Y, Dong L, Ma Y, Liu C, Song W, Wang F, Zhang J, et al: DNA methylation downregulated mir-10b acts as a tumor suppressor in gastric cancer. Gastric Cancer 18: 43-54, 2015.

4. Qiu T, Zhou X, Wang J, Du Y, Xu J, Huang Z, Zhu W, Shu Y and Liu P: miR-145, miR-133a and miR-133b inhibit proliferation, migration, invasion and cell cycle progression via targeting transcription factor Sp1 in gastric cancer. FEBS Lett 588: 1168-1177, 2014.

5. John B, Enright AJ, Aravin A, Tuschl T, Sander C and Marks DS: Human MicroRNA targets. PLoS Biol 2: e363, 2004.

6. Ambros V: The functions of animal microRNAs: Nature 431: 350-355, 2004

7. Lu C, Shan Z, Li C and Yang L: miR-129 regulates cisplatin-resistance in human gastric cancer cells by targeting P-gp. Biomed Pharmacother 86: 450-456, 2017.

8. Zhang Y, Xu W, Ni P, Li A, Zhou J and Xu S: miR-99a and miR-491 regulate cisplatin resistance in human gastric cancer cells by targeting CAPNS1. Int J Biol Sci 12: 1437-1447, 2016.

9. Calin GA, Sevignani C, Dumitru CD, Hyslop T, Noch E, Yendamuri S, Shimizu M, Rattan S, Bullrich F, Negrini M and Croce CM: Human microRNA genes are frequently located at fragile sites and genomic regions involved in cancers. Proc Natl Acad Sci USA 101: 2999-3004, 2004.

10. Karbasy SH, Taheriazam A, Mirghasemi A, Sedaghati F, Shakeri M, Yahaghi E and Bahador R: RETRACTED ARTICLE: Upregulation of miR-300 and downregulation of miR-125b act as potential predictor biomarkers in progression, metastasis, and poor prognosis of osteosarcoma. Tumour Biol, 2015 (Epub ahead of print).

11. Zhang Y, Yan LX, Wu QN, Du ZM, Chen J, Liao DZ, Huang MY, Hou JH, Wu QL, Zeng MS, et al: miR-125b is methylated and functions as a tumor suppressor by regulating the ETS1 proto-oncogene in human invasive breast cancer. Cancer Res 71: 3552-3562, 2011.

12. Guan Y, Yao H, Zheng Z, Qiu G and Sun K: miR-125b targets BCL3 and suppresses ovarian cancer proliferation. Int $\mathrm{J}$ Cancer 128: 2274-2283, 2011.

13. Pan S, Cheng X, Chen H, Castro PD, Ittmann MM, Hutson AW, Zapata SK and Sifers RN: ERManI is a target of miR-125b and promotes transformation phenotypes in hepatocellular carcinoma (HCC). PLoS One 8: e72829, 2013. 
14. Nishida N, Yokobori T, Mimori K, Sudo T, Tanaka F, Shibata K, Ishii H, Doki Y, Kuwano H and Mori M: MicroRNA miR-125b is a prognostic marker in human colorectal cancer. Int J Oncol 38: 1437-1443, 2011.

15. Amir S, Ma AH, Shi XB, Xue L, Kung HJ and Devere White RW: Oncomir miR-125b suppresses p14(ARF) to modulate p53-dependent and p53-independent apoptosis in prostate cancer. PLoS One 8: e61064, 2013.

16. Yuxia M,Zhennan T and Wei Z: Circulating miR-125b is a novel biomarker for screening non-small-cell lung cancer and predicts poor prognosis. J Cancer Res Clin Oncol 138: 2045-2050, 2012.

17. Ueda T, Volinia S, Okumura H, Shimizu M, Taccioli C, Rossi S, Alder H, Liu CG, Oue N, Yasui W, et al: Relation between microRNA expression and progression and prognosis of gastric cancer: A microRNA expression analysis. Lancet Oncol 11: 136-146, 2010

18. Li X, Zhang Y, Zhang H, Liu X, Gong T, Li M, Sun L, Ji G, Shi Y, Han Z, et al: miRNA-223 promotes gastric cancer invasion and metastasis by targeting tumor suppressor EPB41L3. Mol Cancer Res 9: 824-833, 2011.

19. Wu JG, Wang JJ, Jiang X, Lan JP, He XJ, Wang HJ, Ma YY, Xia YJ, Ru GQ, Ma J, et al: miR-125b promotes cell migration and invasion by targeting PPP1CA-Rb signal pathways in gastric cancer, resulting in a poor prognosis. Gastric Cancer 18: 729-739, 2015.

20. Fassan M, Pizzi M, Realdon S, Balistreri M, Guzzardo V, Zagonel V, Castoro C, Mastracci L, Farinati F, Nitti D, et al: The HER2-miR125a5p/miR125b loop in gastric and esophageal carcinogenesis. Hum Pathol 44: 1804-1810, 2013.

21. Jin MH, Nam AR, Park JE, Bang JH, Bang YJ and Oh DY: Resistance mechanism against trastuzumab in HER2-positive cancer cells and its negation by Src inhibition. Mol Cancer Ther: pii: molcanther.0669.2016, 2017.

22. Sun R, Shen J, Gao Y, Zhou Y, Yu Z, Hornicek F, Kan Q and Duan Z: Overexpression of EZH2 is associated with the poor prognosis in osteosarcoma and function analysis indicates a therapeutic potential. Oncotarget 7: 38333-38346, 2016.

23. Livak KJ and Schmittgen TD: Analysis of relative gene expression data using real-time quantitative PCR and the 2(-Delta Delta C(T)) method. Methods 25: 402-408, 2001

24. Bousquet M, Quelen C, Rosati R, Mansat-De Mas V, La Starza R, Bastard C, Lippert E, Talmant P, Lafage-Pochitaloff M, Leroux D, et al: Myeloid cell differentiation arrest by miR-125b-1 in myelodysplastic syndrome and acute myeloid leukemia with the $\mathrm{t}(2 ; 11)(\mathrm{p} 21 ; \mathrm{q} 23)$ translocation. J Exp Med 205: 2499-2506, 2008 .
25. Chapiro E, Russell LJ, Struski S, Cavé H, Radford-Weiss I, Valle VD, Lachenaud J, Brousset P, Bernard OA, Harrison CJ and Nguyen-Khac F: A new recurrent translocation $\mathrm{t}(11 ; 14)$ (q24;q32) involving IGH@ and miR-125b-1 in B-cell progenitor acute lymphoblastic leukemia. Leukemia 24: 1362-1364, 2010.

26. Song F, Yang D, Liu B, Guo Y, Zheng H, Li L, Wang T, Yu J, Zhao Y, Niu R, et al: Integrated microRNA network analyses identify a poor-prognosis subtype of gastric cancer characterized by the miR-200 family. Clin Cancer Res 20: 878-889, 2014.

27. Berg M and Soreide K: EGFR and downstream genetic alterations in KRAS/BRAF and PI3K/AKT pathways in colorectal cancer: Implications for targeted therapy. Discov Med 14: 207-214, 2012.

28. Ching CB and Hansel DE: Expanding therapeutic targets in bladder cancer: The PI3K/Akt/mTOR pathway. Lab Invest 90: 1406-1414, 2010

29. Siegfried Z, Bonomi S, Ghigna C and Karni R: Regulation of the Ras-MAPK and PI3K-mTOR signalling pathways by alternative splicing in cancer. Int J Cell Biol 2013: 568931, 2013.

30. Schneider MR and Yarden Y: The EGFR-HER2 module: A stem cell approach to understanding a prime target and driver of solid tumors. Oncogene 35: 2949-2960, 2016.

31. Thiel A and Ristimäki A: Targeted therapy in gastric cancer. APMIS 123: 365-372, 2015.

32. Teplinsky E and Muggia F: Targeting HER2 in ovarian and uterine cancers: Challenges and future directions. Gynecol Oncol 135: 364-370, 2014.

33. D'Amato V, Raimondo L, Formisano L, Giuliano M, De Placido S, Rosa R and Bianco R: Mechanisms of lapatinib resistance in HER2-driven breast cancer. Cancer Treat Rev 41: 877-883, 2015.

34. Vilquin P, Donini CF, Villedieu M, Grisard E, Corbo L, Bachelot T, Vendrell JA and Cohen PA: MicroRNA-125b upregulation confers aromatase inhibitor resistance and is a novel marker of poor prognosis in breast cancer. Breast Cancer Res 17: 13, 2015.

35. Yagishita S, Fujita Y, Kitazono S, Ko R, Nakadate Y, Sawada T, Kitamura Y, Shimoyama T, Maeda Y and Takahashi F, et al: Chemotherapy-regulated microRNA-125-HER2 pathway as a novel therapeutic target for trastuzumab-mediated cellular cytotoxicity in small cell lung cancer. Mol Cancer Ther 14: $1414-1423,2015$ 